\title{
$O$ Cortiço: um estudo dos personagens à luz da Sociologia do Romance
}

\author{
Vivian C. Alves de Carvalho*
}

\begin{abstract}
Resumo: $O$ presente ensaio analisa $O$ Cortiço, de Abstract: The present paper analyzes Aluísio Aluísio Azevedo, focando os personagens, com o Azevedo's The Slum, focusing on the characters. It objetivo de mostrar que as relações sociais aims to show that the social relations presented in the apresentadas na obra refletem a condição do Brasil no novel reflect the conditions of Brazil in the end of the final do século XIX, época em que a urbanização se $19^{\text {th }}$ century, a time when the urbanization was acentuava cada vez mais, e o capitalismo se fortalecia growing, and the capitalism was becoming brutally brutalmente. O trabalho é desenvolvido com base na stronger. The paper is based on the Sociology of the Sociologia do Romance, na concepção de Georg Novel, according to Georg Lukács's concepts, and Lukács, e se apóia na visão crítica de Antonio Candido, relies on Antonio Candido's critical view in his essay em seu ensaio De cortiço a cortiço.

De cortiço a cortiço.
\end{abstract}

Palavras-chave: $O$ Cortiço; personagens; Sociologia Keywords: The Slum ( $O$ Cortiço); characters; do Romance; urbanização; capitalismo. Sociology of the Novel; urbanization; capitalism.

\section{Primeira Parte}

O Cortiço (1890), de Aluísio Azevedo, é um dos romances mais interessantes da literatura brasileira. Sua leitura nos proporciona uma visão clara do momento histórico pelo qual o país passava - um momento em que a consciência do subdesenvolvimento começava a aflorar e a se tornar elemento inescapável aos romancistas brasileiros.

O herói romanesco, que antes era um burguês alienado dos problemas de seu país e de quaisquer questões políticas ou sociais, como podemos ver em Joaquim Manoel de Macedo, por exemplo, é agora um herói que pertence à classe trabalhadora, que sente na pele as conseqüências da ascensão da lógica capitalista. Em $O$ Cortiço, como aponta Antonio Candido no ensaio De cortiço a cortiço, "está presente o mundo do trabalho, do lucro, da competição, da exploração econômica visível, que dissolvem a fábula e sua intemporalidade" (CANDIDO, 2004, p. 128).

Segundo Georg Lukács, em A Teoria do Romance, "o romance é a forma da aventura do valor próprio da interioridade; seu conteúdo é a história da alma que sai a campo para

\footnotetext{
* Mestranda em Literatura Brasileira pela UFRGS. E-mail: carvalho_vivian@yahoo.com.br
} 
conhecer a si mesma, que busca aventuras para por elas ser provada e, pondo-se à prova, encontrar a sua própria essência" (LUKÁCS, 2000, p. 91). O herói do romance é um indivíduo problemático, que está sempre em busca de algo que lhe falta. Ou seja, não temos mais o herói da epopéia, aquele herói passivo, que vive num mundo presidido por deuses, para usar a expressão do próprio LUKÁCS (2000), e que, portanto, não é ameaçado pelos demônios - uma vez que os deuses sempre têm de triunfar sobre os eles (p. 91).

\begin{abstract}
A psicologia do herói romanesco é o campo de ação do demoníaco. A vida biológica e sociológica está profundamente inclinada a apegar-se a sua própria imanência: os homens desejam meramente viver, e as estruturas, manter-se intactas; se os homens, por vezes acometidos pelo poder do demônio, não excedessem a si mesmos de modo infundado e injustificável e não revogassem os fundamentos psicológicos e sociológicos de sua existência, o distanciamento e a ausência de deus efetivo emprestaria primazia absoluta à indolência e à auto-suficiência dessa vida que apodrece em silêncio. Súbito descortina-se então o mundo abandonado por deus [...] (LUKÁCS, 2000, p. 92).
\end{abstract}

Ou seja, o herói do romance vive num mundo abandonado pelos deuses - está à própria sorte. Sua luta é uma luta por sobrevivência, permeada por obstáculos que muitas vezes independem de sua própria vontade, mas que redefinem seu destino.

Em $O$ Cortiço, temos uma gama de personagens que podem ser agrupados em categorias que nos ajudam a visualizar melhor o significado de sua trajetória nesse mundo abandonado por deus. Dessa forma, a partir da sociologia de LUKÁCS (2000) e com o apoio de Antonio Candido (2004), procurarei fazer uma análise do romance de Aluísio Azevedo, focando os personagens, com o objetivo de mostrar que as relações sociais apresentadas na obra refletem a condição do Brasil naquele momento, final do século XIX, em que a urbanização se acentuava cada vez mais e o capitalismo se fortalecia brutalmente, num processo cujas conseqüências são sofridas até os dias de hoje por todos nós.

CANDIDO (2004), a partir de um raciocínio sobre o dito popular dos três pês - "para o escravo são necessários três P. P. P., a saber, Pau, Pão e Pano" - apresenta três categorias de personagens presentes em $O$ Cortiço: a primeira é a do português, que inclui João Romão, Miranda e Jerônimo, "variedades do branco europeu, desprezado de maneira ambivalente pelo nativo mas pronto para suplantá-lo e tornar-se o verdadeiro senhor" (CANDIDO, 2004, p. 114). A segunda categoria seria a do negro, incluindo também o mestiço, "a arraia miúda dos cortiços, que mesmo quando etnicamente branca é socialmente negra" (CANDIDO, 2004, p. 114). Aqui poderíamos incluir Firmo, Rita Baiana, Pombinha, etc. E, finalmente, a terceira categoria, redução biológica que, segundo o crítico, transcende o cunho naturalista, é a do animal, ou seja, "a própria redução do homem à condição de besta de carga, explorada para 
formar o capital dos outros" (CANDIDO, 2004, p. 114). E nessa última estão todos, negros e brancos.

Avançando em seu raciocínio, Antonio Candido (2004) elabora uma equação na qual a primeira categoria corresponde ao explorador capitalista; a segunda, ao trabalhador reduzido a escravo; e a terceira, ao homem socialmente alienado, rebaixado ao nível do animal.

Considerando o grande número de personagens que habitam $O$ Cortiço e a impossibilidade de se fazer uma análise de cada um deles, penso que tal agrupamento seja muito produtivo e eficiente. Embora cada personagem seja um indivíduo diferente, dotado de particularidades interessantes, do ponto de vista sociológico é possível fazer uma separação por classes, tornando o estudo ao mesmo tempo mais objetivo e mais profundo.

\section{Segunda Parte}

João Romão, primeiro integrante do grupo do português, é um homem ambicioso, cujas ações são movidas por um único motivo: ascender socialmente. Abusa de qualquer pessoa para atingir seu objetivo e não hesita em desprezar e humilhar as pessoas quando já não precisa mais delas; não demonstra o menor resquício de amor ou respeito por ninguém, pois na sua visão todos a sua volta são instrumentos para a sua própria ascensão. João Romão enriquece por meios escusos e em momento algum demonstra peso na consciência.

Por outro lado, não há como negar que, apesar de todos os abusos que cometeu, João Romão, juntamente com Bertoleza - escrava que ele fingiu alforriar - trabalhou muito e sofreu muitas privações para acumular suas riquezas. Nesse sentido, de acordo com CANDIDO (2004), ele se nivela ao escravo (e, portanto, ao animal), que também "trabalhava como um burro". A diferença entre ambos está justamente no fato de que o português tem a possibilidade de juntar dinheiro e subir na vida, inserindo-se até nas mais altas camadas sociais (CANDIDO, 2004, p. 110).

Miranda, inicialmente grande rival de João Romão, é também um interesseiro. É casado com Estela e sabe que esta mantém uma relação extraconjugal, porém faz vista grossa, já que sua posição social se deve à riqueza dela. Ao contrário de João Romão, que só trabalha, Miranda aproveita a vida, goza as facilidades que sua condição lhe proporciona. Devido à influência da mulher, conquista o título de Barão. Tal fato desperta uma profunda inveja em João Romão, que, entretanto, demonstrando todo o seu parasitismo social, resolve se tornar grande amigo do novo nobre, a ponto de, mais tarde, já livre de Bertoleza, casar-se com sua filha, Zulmira. 
Jerônimo é o personagem em que mais se percebe a influência do ambiente. Inicialmente é descrito como um Hércules, belo, forte, nobre. Trabalhador, pai de família, não sai de casa nem para festas e é o funcionário exemplar de João Romão. Porém, basta ver a sensual Rita Baiana para seu comportamento começar a se alterar gradativa, mas radicalmente, até o ponto em que abandona completamente seus traços portugueses e assume características de brasileiro legítimo.

Através desses três representantes do branco europeu, podemos perceber alguns fatores com relação ao posicionamento do próprio Aluísio Azevedo sobre a presença do português no Brasil. Segundo CANDIDO (2004), a ascensão de João Romão, implicitamente tornada centro da narrativa, "tem para o romancista um caráter de paradigma, inclusive devido à reação suscitada no brasileiro mais ou menos ressentido pela constituição das fortunas portuguesas daquele tempo" (p. 111). Ainda de acordo com CANDIDO (2004), a acumulação de João Romão seria para Aluísio um símbolo da exploração do brasileiro pelo estrangeiro, e é por isso que quase não existe sentimento de injustiça social: porque o nacionalismo e a xenofobia se sobressaem (p. 112).

Miranda, ainda que de modo diverso, também se inclui nesse paradigma. Sua ascensão também acontece como resultado da exploração do brasileiro, só que no seu caso, ao invés de escravizar as classes inferiores, ele escolhe um outro caminho: o casamento por interesse. Miranda atinge seu prestígio explorando a influência de sua esposa, que de fato pertence à alta sociedade brasileira.

Dessa forma, partindo da análise feita por Antonio Candido (2004), tanto João Romão quanto Miranda integram o, digamos, subgrupo do português que chega e vence o meio, que não se submete às forças dele (CANDIDO, 2004, p. 112). E essa vitória se dá através da exploração. Já Jerônimo, que "opta pela adesão à terra e é tragado por ela" (CANDIDO, 2004, p. 113), seria o português que chega e é vencido pelo meio. Os três representam o explorador capitalista. João Romão e Miranda são os que conseguiram exercer a sua dominância, e Jerônimo, o que não conseguiu "ser agente no processo de espoliar e acumular" (CANDIDO, 2004, p. 114).

\section{Terceira parte}

A categoria do negro, na qual se incluem todos os brasileiros que vivem no cortiço negros, mestiços e todos aqueles que mesmo tendo a pele branca são socialmente negros, para reforçar a expressão de Antonio Candido (2004), sofre a violência resultante da ambição do 
português, mas também assume posição de carrasco contra o vizinho que demonstra um pouco mais de fraqueza. Vejamos as palavras de Antonio Candido:

Daí a grosseria agressiva da formulação, feita para não deixar dúvidas: eu, brasileiro nato, livre, branco, não posso me confundir com o homem de trabalho bruto, que é escravo e de outra cor; e odeio o português, que trabalha como ele e acaba mais rico e mais importante do que eu, sendo além disso mais branco. Quanto mais ruidosamente eu proclamar meus débeis privilégios, mais possibilidades terei de ser considerado branco, gente bem, candidato viável aos benefícios que a Sociedade e o Estado devem reservar aos seus prediletos". (CANDIDO, 2004, p. 113).

Ou seja, além do ressentimento do brasileiro pelo estrangeiro que faz a vida no seu país e às suas custas, ainda há o desconforto causado pela equivalência de posição entre o branco e o negro, descendente de escravos, homem nascido para o trabalho pesado. O branco se revolta por ser dominado pelo português, que além de tudo é mais branco que ele, ao mesmo tempo em que não acha perfeitamente justo pisar no negro, que no fim das contas pertence à mesma classe.

CANDIDO (2004) vai adiante:

\begin{abstract}
Se estiver na camada de camada de cima, asseguro deste modo a minha posição e desmascaro os que estão por baixo: portugueses pobres, gente de cor, brancos do meu tipo que podem cobiçar o meu lugar. Se estiver em camada inferior, devo gritar ainda mais alto, para me fazer como os de cima e evitar qualquer confusão com os que estão mais abaixo. Por isso eu empurro o meu vizinho de baixo e sou empurrado pelo de cima, todos querendo ganhar sofregamente o direito de serem reconhecidos nos termos implícitos do dito espirituoso. Uma espécie de brincadeira grossa de gata-pariu onde cada um procura desalojar o vizinho e do qual saem sempre expulsos o mais fraco, o menos branco, o que se envolve mais pesadamente no processo de produção (CANDIDO, 2004, p. 113).
\end{abstract}

Em outras palavras, o esforço dessas pessoas supera a mera necessidade de sobrevivência. Ao que parece, de acordo com o raciocínio de CANDIDO (2004), os pares que pertencem a "arraia miúda" procuram se sobressair, de tal maneira que consigam estar sempre um degrau acima do resto dos companheiros. Nesse salve-se quem puder, aquele que se deixa submeter - o negro, que por razões históricas se sente inferior, por mais que tente exercer algum poder - acaba eliminado da disputa, contentando-se com a posição de besta de carga.

Em meio ao imenso e variado leque de personagens d' $O$ Cortiço, podemos citar alguns que se enquadrariam na categoria descrita acima. Um deles é o Velho Botelho. Típico exemplo de parasita, é agregado da família de Miranda e age sempre em favor dos próprios interesses. Tem uma função decisiva no desfecho do romance ao ajudar João Romão a se livrar de Bertoleza para se casar com Zulmirinha. Ou seja, Botelho não hesita em prejudicar o próximo para favorecer seus interesses.

A própria Bertoleza, que na verdade é uma personagem praticamente sem voz no romance, é a que mais sofre abusos e de quem João Romão mais se aproveita. Ele finge 
alforriá-la, e monta o cortiço com sua ajuda; usa da sua força para fazê-la trabalhar incansavelmente. Assim, Bertoleza pensa que é livre, mas não o é nem no papel e nem na realidade, pois trabalha de sol a sol para que João Romão consiga tudo o que quer e não recebe nada em troca. E à medida que o tempo passa, a escrava é descrita como algo mais e mais repugnante - do ponto de vista do seu senhor, é claro. $\mathrm{O}$ único momento em que alguma voz é dada a Bertoleza é quando esta descobre a traição de João Romão; seu grito de liberdade é o suicídio. Portanto, temos mais uma prova de que, n'O Cortiço, o negro - nascido para ser escravo e trabalhar como animal - não consegue sair da sua condição de subordinado ao branco, mesmo que na teoria este não seja em nada superior.

Rita Baiana, representação da sensualidade brasileira, mulata, alegre, pouco disposta a ter um relacionamento amoroso estável, é também um exemplo da subordinação do brasileiro ao estrangeiro. Ainda que tenha sido a grande responsável pela transformação de Jerônimo, ela também acaba sendo dominada por ele. Não podemos esquecer que, logo que percebe o interesse de Jerônimo, Rita abandona o mulato Firmo e seduz o português. É claro que a baiana enxerga no português uma possibilidade de prosperar que não existia ao lado do antigo companheiro, que tinha a mesma condição que ela.

E dessa maneira temos uma amostra do que seria a categoria do brasileiro pobre, sem título de nobreza. Sendo branco ou negro, sua posição será sempre inferior; seu trabalho será sempre o trabalho pesado, submisso ao branco superior que precisa dele para manter seu poder e aumentar sua riqueza. Portanto, citando CANDIDO (2004) novamente, em relação ao explorador capitalista, esta seria a classe do "trabalhador reduzido a escravo" (p.114).

\section{Quarta Parte}

CANDIDO (2004) diz:

Mas acima dessas reduções de cientificismo naturalista há uma redução maior, que as ultrapassa e atinge todos os personagens na sua humanidade, para lá do processo econômico: refiro-me ao substrato comum de animalidade, ou que melhor nome tenha (CANDIDO, 2004, p.122).

Entramos, então, na análise da terceira e última categoria: a do 'homem reduzido a animal', à qual pertencem todos os personagens d'O Cortiço. O crítico prossegue:

O branco, predatório ou avacalhado, sem meio-termo; o mulato e o negro, desordenados, fatores de desequilíbrio, todos têm na economia d' $O$ Cortiço uma espécie de destino animal comum, acentuado pelo gosto naturalista da visão fisiológica, a tendência a conceber a vida 
como soma das atividades do sexo e da nutrição, sem outras esferas significantes (CANDIDO, 2004, p.122).

Seguindo essa linha de pensamento, temos a animalização do branco europeu no sentido de reforçar a superioridade moral e social dos mesmos. Os brasileiros, por outro lado, são caracterizados por aquilo que, bem ou mal, faz parte da vida de qualquer ser humano prazer sexual e necessidade de alimentação. Não é nenhuma novidade falar em animalização quando se trata de $O$ Cortiço, porém, dentro da proposta de se fazer uma análise sociológica dos personagens do romance, este é um aspecto que não pode deixar de ser mencionado.

É importante notar também que não só os personagens individualmente são caracterizados de forma animalizada, mas o próprio cortiço, como um conjunto, é descrito como algo orgânico, vivo, desde o início da narrativa. Vejamos o parágrafo final do primeiro capítulo do livro, em que é apresentado o cortiço que estava surgindo:

E naquela terra encharcada e fumegante, naquela umidade quente e lodosa, começou a minhocar, a esfervilhar, a crescer, um mundo, uma coisa viva, uma geração que parecia brotar espontânea, ali mesmo, daquele lameiro, e multiplicar-se como larvas no esterco (AZEVEDO, 1997 , p. 28).

Não raro encontramos textos críticos sugerindo que o grande personagem d' $O$ Cortiço é o próprio cortiço. Sendo assim, a descrição do personagem principal não difere muito da dos secundários. Ainda que todos eles sejam apenas figurantes em relação ao protagonista, não devemos esquecer que sem os figurantes, não existiria o protagonista. São os habitantes do cortiço que determinam e caracterizam a sua existência. Por isso, para que um grande organismo tenha vida, é necessário que todos os seus componentes também tenham.

Entretanto, é preciso observar que essa "orientação científica", na expressão de Antonio Candido (2004), não é usada com o intuito de meramente rebaixar o ser humano. Existe, sim, um nivelamento do homem ao animal, mas, avançando a interpretação para o debate sociológico, citando CANDIDO (2004) novamente, o que Aluísio Azevedo (1997) faz é tentar mostrar que os homens, assim como os animais, estão sujeitos às leis da natureza. $\mathrm{A}$ tal seleção natural, de Darwin, também se aplica aos seres humanos. As relações sociais são tão violentas e brutais quanto as leis que regem o mundo animal, segundo as quais o animal mais forte devora o mais fraco sem qualquer sentimento de culpa. E, não por acaso, é exatamente isso que acontece n' $O$ Cortiço o tempo todo. Portanto, muito mais do que recurso de estilo naturalista, temos no romance de Aluísio Azevedo (1997) uma crítica bastante consciente aos rumos que o sistema capitalista estava dando à sociedade brasileira.

CANDIDO (2004) apresenta mais uma idéia interessante no seguinte parágrafo: 
A perspectiva naturalista ajuda a compreender o mecanismo d' $O$ Cortiço, porque o mecanismo do cortiço nele descrito é regido por um determinismo estrito, que mostra a natureza (meio) condicionando o grupo (raça) e ambos definindo as relações humanas na habitação coletiva. Mas esta força determinante de fora para dentro é contrabalançada e compensada por uma força que atua de dentro para fora: o mecanismo de exploração do português, que rompe as contingências e, a partir do cortiço, domina a raça e supera o meio. O projeto do ganhador de dinheiro aproveita as circunstâncias, transformando-as em vantagens, e esta tensão ambígua pode talvez ser considerada um dos núcleos germinais da narrativa (CANDIDO, 2004, p. 119).

A força do branco explorador é tão intensa quanto a força que o meio exerce sobre os habitantes do cortiço. E ambas surtem um efeito negativo sobre aquelas pessoas. Como diz CANDIDO (2004) no parágrafo seguinte, “aquilo que é condição de esmagamento para o brasileiro, seria a condição de realização para o explorador de fora, pois sempre a pobreza e a privação foram as melhores e mais seguras fontes de riqueza" (p.119).

Dessa maneira, as duas forças agem contra o brasileiro, negro e pobre; a sua natureza não lhe permite o avanço. Já no caso do branco europeu, sua natureza - superior - favorece, mas não garante, a posição de dominador. Jerônimo não consegue resistir à sensualidade da mulata brasileira, porém, ele não é capaz de transformá-la numa mulher de alta classe; o que acontece é justamente o contrário - já que Jerônimo é o estrangeiro naquele meio, ele sofre a influência e acaba se tornando pertencente à classe inferior. Já no caso de João Romão e Bertoleza, ainda que em circunstâncias totalmente diferentes, o português em momento algum abandona sua condição de branco superior, embora também trabalhe de sol a sol.

Resumindo, os destinados à inferioridade trabalham pesado para sobreviver, mas nunca chegam à classe mais alta, pois são objetos da exploração dos de raça superior. Estes trabalham tão pesado quanto os outros, mas têm a possibilidade de melhorar de vida cada vez mais, através da acumulação de capital que a utilização da mão de obra barata ou escrava lhe proporciona. E assim, conseguimos visualizar a categoria a que CANDIDO (2004) se refere como a do "omem socialmente alienado, rebaixado ao nível do animal" (p.114).

\section{Quinta Parte}

Nas palavras de LUKÁCS (2000):

O indivíduo épico, o herói do romance, nasce desse alheamento em face do mundo exterior. Enquanto o mundo é intrinsecamente homogêneo, os homens também não diferem qualitativamente entre si: claro que há heróis e vilões, justos e criminosos, mas o maior dos heróis ergue-se somente um palmo acima da multidão de seus pares, e as palavras solenes dos mais sábios são ouvidas até pelos mais tolos. (LUKÁCS, 2000, p. 66). 
Ou seja, o herói do romance não é um ser superior, uma divindade, um indivíduo passivo, como o da epopéia - é um herói que está apenas um palmo acima de seus pares. Há heróis e vilões, mas em essência eles não diferem entre si - são humanos.

Os personagens d'O Cortiço são boas representações desse indivíduo épico descrito por LUKÁCS (2000). O romance, “epopéia de mundo abandonado por deus”, nos apresenta um herói que está em busca de algo; é a forma que representa o mundo fragmentado, o mundo que não pode mais ser representado como uma totalidade. Nesse sentido, a obra de Aluísio Azevedo pode perfeitamente ser contemplada pela Teoria do Romance, pois o cortiço é um universo fragmentado, que de alguma maneira simboliza uma realidade também desprovida de totalidade: a sociedade brasileira.

Em artigo sobre a Teoria do Romance, Antônio Sanseverino afirma:

Como cada gênero está enraizado em uma sociedade historicamente delimitada, uma nova forma é índice de um novo mundo, uma superação do herói demoníaco. Um novo sujeito histórico estaria aparecendo no horizonte histórico, consciente de si (como no romance), porém integrado ao mundo (como na epopéia), expressão da coletividade. Talvez não seja exagero ler, a partir dessa expectativa, o proletariado como o novo herói (...), que deve estar consciente de seu papel, enraizado em sua classe (proletário) a fim de remissão de uma humanidade alienada dos valores autênticos (SANSEVERINO, 2003, p.93).

A partir dessa perspectiva, é fácil conceber $O$ Cortiço como um romance, nos moldes da teoria de LUKÁCS (2000), e seus personagens como heróis representantes de uma coletividade. Seguindo a distinção de CANDIDO (2004), o explorador em oposição ao explorado, e ambos socialmente alienados.

No universo criado por Aluísio Azevedo, cada personagem, na sua individualidade, é uma representação da coletividade. Dentro da realidade fragmentada de cada um, está uma porção daquilo que é experimentado por todos. Assim, o destino de um é o destino de todos no contexto de seu grupo. E através dessa análise podemos perceber o lado mais crítico da obra. A percepção de Aluísio sobre a estrutura social que estava se formando é muito precisa, e não pode ser ignorada ou reduzida a um mero recurso estilístico. Na construção de cada personagem e da obra como um todo é visível a preocupação não em retratar a vida como ela é, mas em criticar, em problematizar a maneira como a sociedade estava se moldando naquele momento.

\section{Referências}

AZEVEDO, Aluísio. O Cortiço. Coleção Clássicos da Literatura. Klick Editora, 1997. 
CANDIDO, Antonio. De cortiço a cortiço. In: O Discurso e a Cidade. Rio de Janeiro: Ouro sobre Azul, 2004.

LUKÁCS, Georg. A Teoria do Romance. São Paulo: Duas Cidades; Ed. 34, 2000.

SANSEVERINO, Antônio Marcos Vieira. A Força Messiânica e a Teoria do Romance. In: BORDINI, Maria da Glória (org.). Lukács e a Literatura. Porto Alegre: EDIPUCRS, 2003. 